\title{
GCU
}

Glasgow Caledonian

University

University for the Common Good

\section{Carnosic acid attenuates acrylamide-induced retinal toxicity in zebrafish embryos}

Albalawi, Aishah; Alhasani, Reem Hasaballah A.; Biswas, Lincoln; Reilly, James; Akhtar, Saeed; Shu, Xinhua

Published in:

Experimental Eye Research

DOI:

10.1016/j.exer.2018.06.018

Publication date:

2018

Document Version

Author accepted manuscript

Link to publication in ResearchOnline

Citation for published version (Harvard):

Albalawi, A, Alhasani, RHA, Biswas, L, Reilly, J, Akhtar, S \& Shu, X 2018, 'Carnosic acid attenuates acrylamideinduced retinal toxicity in zebrafish embryos', Experimental Eye Research, vol. 175, pp. 103-114.

https://doi.org/10.1016/j.exer.2018.06.018

\section{General rights}

Copyright and moral rights for the publications made accessible in the public portal are retained by the authors and/or other copyright owners and it is a condition of accessing publications that users recognise and abide by the legal requirements associated with these rights.

Take down policy

If you believe that this document breaches copyright please view our takedown policy at https://edshare.gcu.ac.uk/id/eprint/5179 for details of how to contact us. 
1 Carnosic acid attenuates acrylamide-induced retinal toxicity in zebrafish embryos

2 Aishah Albalawi ${ }^{1,3}$, Reem Hasaballah A Alhasani ${ }^{1,4}$, Lincoln Biswas ${ }^{1}$, James Reilly ${ }^{1}$, Saeed Akhtar ${ }^{2}$, 3 Xinhua Shu ${ }^{1}$

4

51 Department of Life Sciences, Glasgow Caledonian University, Cowcaddens Rd, G4 0BA, Glasgow, $6 \quad \mathrm{UK}$

7 2. Cornea Research Chair, Department of Optometry, King Saud University PO Box 10219, Riyadh

8 11433, Kingdom of Saudi Arabia

9 3. Department of Biology, University of Tabuk, Tabuk, Saudi Arabia

10

4. Department of Biology, Umm Al-Qura University, Makkah, Saudi Arabia

11

12

13

14

15

16

17

18

19

20

21

22

23

24

25

26

27 


\section{Abstract}

30

Acrylamide (ACR) is a water-soluble chemical used widely in industry, which can be formed in tobacco smoke and in starchy foods cooked at high temperatures. ACR is considered to be a neurotoxin, genotoxin and carcinotoxin. Previous studies reported that ACR-exposed workers and experimental animals exhibited visual function defects, although the underlying mechanisms have not been elucidated. In this study, we found that zebrafish embryos exposed to $1 \mathrm{mM}$ and $2 \mathrm{mM}$ ACR showed significantly increased reactive oxygen species (ROS), decreased expression of the antioxidant genes Sod1, Sod2, Catalase, GPX1 and $\mathrm{Nrf2}$, reduced activity of superoxide dismutase (SOD) and catalase, and elevated malondialdehyde (MDA), compared with control embryos. ACR exposure caused loss of both rod and cone photoreceptor cells through Caspase-3-dependent apoptotis. When embryos were simultaneously exposed to ACR and the natural antioxidative substance carnosic acid (CA), the presence of the latter $(10 \mu \mathrm{M})$ markedly counteracted the above ACR-induced toxic effects. Our data suggest that CA can protect photoreceptor cells against ACR-induced oxidative damage and has a potential for neuroprotection of visual function in humans exposed to ACR.

Keywords Acrylamide, carnosic acid, oxidative damage, retina, zebrafish 


\section{Introduction}

Acrylamide (ACR) is a white substance with a crystalline solid form. It is highly soluble in water and in polar solvents such as acetone, chloroform, methanol and ethanol, but is insoluble in non-polar solvents (Exon, 2006). The numerous polymers of ACR have a range of industrial applications including drinking water and wastewater treatment, mining, crude oil production, paper pulp processing, concrete production, soil and sand treatment, textile processing, photographic emulsion, adhesives and coatings (Dybing et al., 2005; Smith, et al., 2000). It is also commonly used for gel electrophoresis of proteins in research laboratories. ACR can be formed in the preparation of starchy food such as potato chips and cereal products during high temperature (above $120^{\circ} \mathrm{C}$ ) mainly due to the reaction between free amino groups and carbonyl source (Tareke at al., 2002; Zyzak et al., 2003). The ratio of formed ACR in foods depends on cooking conditions, such as temperature and heating time (Zyzak et al., 2003). ACR is also present in cigarette smoke (Smith et al., 2000). Chronic dietary intake of ACR in children has been estimated to be about $0.5-1.9 \mu \mathrm{g} / \mathrm{kg}$ body weight (b.w.) per day; for adolescents, adults and old people it has been estimated to be about $0.4-0.9 \mu \mathrm{g} / \mathrm{kg}$ b.w. per day (EFSA, 2015). Exposure to ACR has been shown to cause neurotoxicity, genotoxicity, developmental toxicity and carcinogenicity in experimental models. Different epidemiological studies have been carried out to investigate the effect of exposure to ACR on humans but have not demonstrated a consistent association between cancer risk and ACR exposure. However, occupational exposure to ACR has been shown to result in an increased risk of neuropathy in humans (EFSA, 2015).

Carnosic acid $\left(\mathrm{CA}, \mathrm{C}_{20} \mathrm{H}_{28} \mathrm{O}_{4}\right)$, a phenolic diterpene, is enriched in the leaves of Lamiaceae plants, and is particularly high in dried leaves of Rosmarinus officinalis L. and Salvia officinalis (Birtić et al., 2015). CA has demonstrated inhibition of oxidative stress and inflammation, suppression of cell proliferation, and antibacterial activity. It is widely reported that CA has a therapeutic potential in different types of cancer, mostly based on in vitro experiments (Moore et al., 2016). CA has also shown neuroprotective effects in experimental models of neurodegenerative diseases, mainly through activation of the antioxidant NRF2/ARE pathway (Bahri et al., 2016). CA has the ability to kill both Gram positive and Gram negative bacteria, though the involved mechanisms are not clear (Birtić et 
al., 2015). Additionally, carnosic acid has been considered as an antioxidant additive in food matrices such as oils, sauces, and meat products (Birtić et al., 2015).

Zebrafish are an effective vertebrate model organism for toxicology due to their small size and transparent embryonic development that can take place ex utero. The transparency of the embryos makes possible the straightforward monitoring of morphological development and the assessment of possible malformations, while identifying toxicity endpoint is also made easier (Hill et al., 2005). Drug administration in zebrafish embryos is quite easy as they can be stored in micro-titre plates and will absorb through their gills and skin any small molecules administered into the wells (McGrath and $\mathrm{Li}, 2008)$. As a vertebrate model, anatomy and function of zebrafish organs closely resemble that of humans. For example, the zebrafish retina has three major cell layers (outer nuclear layer, inner nuclear layer and ganglion cell layer) organized in a laminar pattern similar to that of human retinas (Raghupathy et al., 2013). Zebrafish retina develops early and rapidly, such that the ganglion cells begin to differentiate and become postmitotic between 28 and 32 hours post-fertilization (hpf) (Schmitt and Dowling, 1994; Hu and Easter, 1999). The inner nuclear layer is present by $38 \mathrm{hpf}$, while the photoreceptor cells start to differentiate at 50-54hpf (Hu and Easter, 1999; Schmitt and Dowling, 1999). The outer segments are first observed at 54-60hpf. Retinal lamination starts at $32 \mathrm{hpf}$ and is fully established by 60hpf (Schmitt and Dowling, 1999). Zebrafish demonstrate visual function at 72hpf. Similar to the human retina, zebrafish have a cone-rich retina, providing an excellent model by which to study human retinal degeneration and retinal toxicity (Shu et al., 2010; Zhang et al., 2015).

In the present study we investigated ACR-induced toxicity and evaluated the protective effect of CA in zebrafish embryos. We found ACR treatment caused morphological abnormalities, increased production of reactive oxygen species (ROS), reduced antioxidant capacities, and increased death of photoreceptor cells. When zebrafish were co-exposed to ACR and CA, the above toxic effects were reversed.

\section{Materials and methods}

\subsection{Zebrafish maintenance}

AB strain adult zebrafish (Danio rerio) were maintained in a TECHPLUS aquatic system with a 14/10 hours light/dark photoperiod. Breeding was triggered under light and fertilized embryos were 
collected. Embryos were cultured in $\mathrm{E} 3$ medium $(5 \mathrm{mM} \mathrm{NaCl}, 0.17 \mathrm{mM} \mathrm{KCl}, 0.33 \mathrm{mM} \mathrm{CaCl}, 0.33 \mathrm{mM}$ $\mathrm{MgSO}_{4}$ ) in $28^{\circ} \mathrm{C}$ incubator. $\mathrm{NaCl}, \mathrm{KCl}, \mathrm{CaCl}$ and $\mathrm{MgSO} 4$ were bought from Sigma (Sigma-Aldrich

114 Company Ltd., UK). All animal experiments were carried out in compliance with the UK Animals 115 (Scientific Procedures) Act 1986 under the project licence PPL 60/4169.

\subsection{Zebrafish embryo treatment}

Initial toxicity tests of ACR and CA (Sigma-Aldrich Company Ltd., UK) in zebrafish embryos were performed in 24-well plates. Zebrafish embryos used for all experiments were at 6hpf. All tests were run in triplicate and each well contained 10 embryos in $500 \mu 1$ drug solutions. Embryos were exposed to ACR at the concentration of $1,2,3,4$ or $5 \mathrm{mM}$, or to CA at the concentration of $10,20,30,40$ or $50 \mu \mathrm{M}$. During the experimental period, the exposure solutions were renewed daily and dead embryos were discarded. Morphological abnormalities in treated embryos were carefully observed under a microscope (AMG Introduces EVOS fl) and images were captured. Mortality and other teratogenic defects such as altered heartbeat, hatching, edema, and curved body were recorded under a stereo light microscope at 48, 72, 96 and $120 \mathrm{hpf}$.

Based on the initial toxicity tests, we chose $10 \mu \mathrm{M} \mathrm{CA}$ and 1 and $2 \mathrm{mM}$ ACR for subsequent experiments. Embryos at 6hpf were treated with ACR (1 or $2 \mathrm{mM})$ only, or together with CA $(10 \mu \mathrm{M})$. The treatments were performed in triplicate, with each well containing 10 embryos. Control embryos were treated with 0.1\% DMSO (Sigma-Aldrich Company Ltd., UK) in E3 medium. The exposure solutions were renewed daily. Morphological deformities in treated embryos were carefully monitored and images were captured under microscopy (AMG Introduces EVOS fl). Mortality and other teratogenic phenotypes (altered heartbeat, hatching, edema, and curved body) were recorded at 48, 72, 96 and 120hpf. After the treatment, embryos were collected for further biochemical and immunohistological analyses.

\subsection{Measurement of reactive oxygen species (ROS)}

Production of ROS in treated and control zebrafish embryos was measured using DCFH-DA (2', 7' dichlorofluorescin diacetate, Sigma-Aldrich Company Ltd., UK) according to the previous description

138 (Tohari et al., 2016). Briefly, zebrafish embryos were euthanized using ms-222 (Sigma-Aldrich Company Ltd., UK) and washed with cold-PBS twice, then homogenized in a cold buffer $(0.32 \mathrm{mM}$ 
sucrose, 20mM HEPES, 1mM MgCl2, 0.5mM of phenylmethyl sulfonylfluoride (PMSF), pH 7.4).

141 The homogenate was centrifuged at $15,000 \times \mathrm{g}$ at $4^{\circ} \mathrm{C}$ for $20 \mathrm{~min}, 20 \mu \mathrm{l}$ of the supernatant was

142 transferred into each well of 96-well plates and incubated with $8.3 \mu 1 /$ well of DCFH-DA solution

$143(20 \mu \mathrm{g} / \mathrm{ml})$. The plate was incubated in the dark at $37^{\circ} \mathrm{C}$ for $30 \mathrm{~min}$, then the fluorescence was measured at $485 \mathrm{~nm}$ (excitation) and $525 \mathrm{~nm}$ (emission) using a Fluostar Optima microplate reader (BMG-labtech). The ROS level was represented as the percentage of relative fluorescence intensity to control after baseline fluorescence correction (Tohari et al., 2016).

\subsection{Quantitative real-time polymerase chain reaction (qRT-PCR)}

Total RNA was extracted from treated and control embryos using Trizol Reagent (Sigma, UK) following the manufacturer's guidance. cDNA was synthesized using a High-Capacity cDNA Reverse Transcription Kit (Thermo Fisher Scientific, UK). Expression of target genes was measured by qRTPCR assay using a Platinum ${ }^{\circledR}$ SYBR ${ }^{\circledR}$ Green PCR kit (Thermo Fisher Scientific, UK) under the following PCR condition: $50^{\circ} \mathrm{C}$ for 2 minutes and $95^{\circ} \mathrm{C}$ for 2 minutes then 40 cycles of $95^{\circ} \mathrm{C}$ for 15 seconds and $60^{\circ} \mathrm{C}$ for 60 seconds. The fluorescence signals were detected at the end of the $60^{\circ} \mathrm{C}$ step. The relative expression of target gene was determined by normalization to the expression of the housekeeping gene ( $\beta$-actin) according to $2^{-\Delta \Delta \mathrm{CT}}$ formula. The primer sequences of targeted genes are listed in Supplementary data, Table S1.

\subsection{Biochemical assays}

Superoxide dismutase (SOD) activity was measured using SOD Detection Kit (STA-340; Cell Biolabs). Briefly, control and treated embryos were homogenized in cold 1x Lysis Buffer (10 mM Tris, $\mathrm{pH} 7.5,150 \mathrm{mM} \mathrm{NaCl}, 0.1 \mathrm{mM}$ EDTA) and centrifuged at $12000 \mathrm{x} \mathrm{g}$ for 10 minutes to collect the tissue lysate supernatant. Samples including a blank were prepared in a 96-well microtiter plate according to the manufacturer's instructions and absorbance was read at $490 \mathrm{~nm}$ on a microplate reader.

Catalase activity was measured using the catalase detection kit (STA-341, Cell Biolabs). Briefly, control and treated embryos were homogenized in cold PBS with 1mM EDTA on ice and centrifuged at $10,000 \mathrm{x}$ g for 15 minutes at $4^{\circ} \mathrm{C}$ to collect supernatant. A catalase standard was set up and catalase 
in individual supernatants was measured in a 96-well plate according to the manufacturer's instructions.

Glutathione (GSH) level was measured using the total glutathion (GSSG/GSH) assay kit (STA312, Cell Biolabs). Briefly, control and treated embryos were homogenized in ice-cold 5\% metaphosphoric Acid and centrifuged at $12,000 \mathrm{rpm}$ for 15 minutes at $4^{\circ} \mathrm{C}$ to collect supernatants. The glutathione standard was set up in a 96-well plate and GSH concentration of individual plate according to the manufacturer's instructions.

\subsection{Western blotting assay}

Total protein was extracted from zebrafish embryos at $120 \mathrm{hpf}$ using the tissue protein extraction supernatants was measured according to the manufacturer's instructions.

Malondialdehyde (MDA) was quantified using an TBARS assay kit (STA-330, Cell Biolabs). Briefly, control and treated embryos were homogenized in PBS containing 1x butylated hydroxytoluene on ice and centrifuged at $10,000 \mathrm{~g}$ for $5 \mathrm{~min}$ to collect the supernatants. An MDA standard was prepared and MDA concentration in individual supernatants was quantified in a 96-well reagent (Thermo Scientific, UK) as described in the manufacturer's protocol, and centrifuged at 13000rpm for 10 minutes. The supernatant was transferred to a $1.5 \mathrm{ml}$ eppendorf tube and protein concentration was measured. Proteins were separated by SDS-PAGE and transferred to nitrocellulose membrane. The membrane was blocked with 5\% milk powder in Tris-Buffered Saline-Tween 20 buffer for 1 hour at room temperature and then incubated with a primary antibody (mouse antiGAPDH antibody, Santa Cruz Biotechnology, Inc., Cat. Sc-32233 or rabbit anti-caspase3 antibody, antibodies online.com, Cat. ABIN1883652 in 1:1000 dilution) overnight at $4^{\circ} \mathrm{C}$. The membrane was washed and then incubated with a secondary antibody (goat anti-rabbit antibody, Cat. 926-32211 or donkey anti-mouse antibody, Cat. 926-68072 (LI-COR Biosciences, USA) in 1:10000 dilution). The signals were visualized by the LI-COR Odyssey FC Imaging System and quantified using Image Studio $^{\mathrm{TM}}$ Lite analysis software (LI-COR).

\subsection{Histology and immunohistochemistry}

Zebrafish embryos at $120 \mathrm{hpf}$ were fixed in $4 \%$ paraformaldehyde (PFA) overnight at $4{ }^{\circ} \mathrm{C}$ then washed with PBS twice. For haematoxylin and eosin (H\&E) staining, embryos were dehydrated with 
$10 \%$ (6mins), 30\% (6mins), 50\% (6mins), 70\% (6mins), 80\% (3x6mins), 90\% (3x6mins) and 100\%

196 (3x6mins) ethanol treatment and embedded in paraffin. $7 \mu \mathrm{m}$ paraffin sections were made in a

197 microtome and rehydrated in series ethanol treatment, then stained with H\&E. Images were taken under a light microscope. For immunostaining, fixed zebrafish embryos were cryoprotected in 5\%, $15 \%$ and $20 \%$ sucrose, then embedded in Cryomatrix medium (VWR, UK) and quickly frozen using dry ice. $10 \mu \mathrm{m}$ sections were cut in a cryomount at $-20^{\circ} \mathrm{C}$ and blocked using blocking buffer $(2 \%$ bovine serum albumin and 5\% sheep serum in PBS) for $1 \mathrm{~h}$ at room temperature. Sections were incubated with a primary antibody (mouse anti-rhodopsin 4D2 antibody, 1:400, Abcam, Cat. Ab98887or anti-arrestin 3 ZPR-1 antibody, 1:500, Abcam, Cat. Ab174435). After washing with PBS three times, sections were incubated with secondary antibody (Alexa fluor 488 goat anti-mouse, 1:500, Abcam, Cat. Ab150113) and mounted with DAPI (1.5 $\mu \mathrm{g} / \mathrm{ml})$ mounting medium (Vectashield Limited). Images were captured using a Zeiss LSM 510 confocal microscope. The morphometric analysis for measuring the length of the photoreceptor layer and fluorescence signals was performed using Image J software (https://imagej.nih.gov/ij/index.html). Length of photoreceptor layer was measured in the central part of individual images taken from $\mathrm{H} \& \mathrm{E}$ stained zebrafish retinal sections. Fluorescence signals (representing stained rod outer segments with anti-rhodopsin 4D2 antibody or stained cone cells with ZPR-1 antibody) were measured by quantifying the fluorescence signals in entire photoreceptor layer of individual images taken from immunostained zebrafish retinal sections.

\subsection{Cell death detection}

Retinal cell death was detected using DeadEndTM fluorometric TUNEL (TdT-mediated dUTP NickEnd Labeling) assay kit (Promega, UK) according to the manufacturer's protocol. Briefly, tissue sections of treated and control zebrafish embryos were fixed with $4 \%$ PFA for 15 minutes at $4{ }^{\circ} \mathrm{C}$, washed with PBS twice, and permeabilized with a proteinase $\mathrm{K}(20 \mu \mathrm{g} / \mathrm{ml})$ solution for $10 \mathrm{~min}$. Tissues were labelled with rTDT reaction mix containing equilibration buffer, fluorescein-12-dUTP and $\mathrm{rTdT}$ enzyme for one hour at $37^{\circ} \mathrm{C}$ and $2 \times \mathrm{SSC}$ was used to stop the reaction. Tissues were washed with PBS and mounted using DAPI mounting media (Vector laboratories). The fluorescein12-dUTP-labeled DNAs were visualized under a Zeiss LSM 800 confocal microscopy.

\subsection{Statistical analysis}


Statistical analysis was performed using GraphPad Prism version 6 software (GraphPad Software Inc.,

224 San Diego, CA) by one-way ANOVA. Data were obtained from three independent experiments and

225 presented as mean \pm SE.

\section{3. Results}

\subsection{Assessment of toxic effects of ACR and CA on zebrafish embryos}

To assess the toxicity of ACR on zebrafish embryos, we treated embryos at 6hpf with different concentrations (1mM, 2mM, 3mM, $4 \mathrm{mM}$ and $5 \mathrm{mM})$ of ACR and monitored the defects at $72 \mathrm{hpf}$. There was no significant increase in mortality of zebrafish embryos treated with 1 or $2 \mathrm{mM}$ of ACR when compared to untreated embryos. However, there was a significant increase in mortality in embryos treated with $3 \mathrm{mM}, 4 \mathrm{mM}$ or $5 \mathrm{mM}$ of ACR when compared to untreated controls. The hatching rate of the embryos exposed to ACR at different concentrations was significantly decreased in a dose-dependent trend when compared to untreated controls; embryos treated with 4 or $5 \mathrm{mM}$ ACR did not hatch. Heart rate was also markedly decreased at 72hpf in ACR-treated embryos compared to controls (Fig. 1A). We also noticed morphological abnormalities such as curved body axis and pericardial edema in embryos exposed to ACR at $2 \mathrm{mM}$ and higher concentrations (Fig. S1). However, embryos exposed to $1 \mathrm{mM}$ ACR exhibited normal morphology at $72 \mathrm{hpf}$. Based on the results from the initial toxicity test, we decided to use 1 and $2 \mathrm{mM}$ ACR for subsequent experiments.

Initially we assessed the toxicity of CA by treating embryos with $\mathrm{CA}$ at $10,20,30,40$ or $50 \mu \mathrm{M}$. At $72 \mathrm{hpf}$ there was no significant difference in mortality, hatching and heart rate of embryos treated with $\mathrm{CA}$ at 10 or $20 \mu \mathrm{M}$ when compared to untreated controls (Fig. 1B). Exposure to CA at higher concentrations (30mM and above) resulted in markedly increased mortality and decreased hatching and heart rate at $72 \mathrm{hpf}$ (Fig. 1B). Based on the initial toxicity data, we chose $10 \mu \mathrm{M}$ CA for subsequent experiments. We examined whether CA could reverse ACR-induced toxic effects on zebrafish embryos and found that co-exposure with ACR and CA resulted in a significant increase in hatching and heart rate when compared to embryos exposed to ACR only (Fig. 1C). embryos. 
Previous studies reported that ACR exposure resulted in significantly increased ROS production in neuron-associated cell lines (Albalawi et al., 2018; Pan et al., 2015) and in rat cortical neurons (Zhang et al., 2014). We investigated whether ACR exposure can increase ROS production in zebrafish embryos. As shown in Fig. 2, relative to untreated controls there was a considerable increase in ROS generation by $184 \%$ and $302 \%$ in zebrafish embryos treated from $6 \mathrm{hpf}$ to $120 \mathrm{hpf}$ with, respectively, $1 \mathrm{mM}$ and $2 \mathrm{mM}$ ACR. However, relative to the ACR-treated embryos the production of ROS was significantly decreased by $47.83 \%$ and $47.96 \%$ when the embryos were co-treated with, respectively, $10 \mu \mathrm{M} \mathrm{CA}+1 \mathrm{mM}$ ACR or $10 \mu \mathrm{M} \mathrm{CA}+2 \mathrm{mM}$ ACR (Fig. 2).

\subsection{ACR caused a decrease in antioxidant capacity and carnosic acid reversed the effect}

Since ROS production was significantly increased in ACR-treated embryos (Fig. 2), we wanted to know if this is due to an imbalance of the antioxidant defence system. We detected expression of antioxidant genes by qRT-PCR and found that expression of Sod1, Sod2, Catalase, GPX1 and Nrf2 genes was significantly decreased in embryos treated with 1 or $2 \mathrm{mM} \mathrm{ACR}$ when compare to control embryos (Fig. 3). When embryos were co-exposed to ACR and CA, expression of these genes was markedly increased, compared to that seen in embryos treated with ACR alone (Fig. 3).

We also investigated the effects of ACR treatment on the activity of superoxide dismutase (SOD) and catalase (CAT). SOD activity was noticeably decreased by $51.23 \%$ and $63.42 \%$ in embryos treated with, respectively, $1 \mathrm{mM}$ or $2 \mathrm{mM}$ ACR, compared to the controls (Fig. 4A). SOD activity was considerably elevated by $160.6 \%$ and $200 \%$ in embryos treated with, respectively, $1 \mathrm{mM}$ ACR + $10 \mu \mathrm{M}$ CA or $2 \mathrm{mM} \mathrm{ACR}+10 \mu \mathrm{M}$ CA, compared to embryos treated with 1 or $2 \mathrm{mM}$ ACR alone (Fig. 4A). Similarly, CAT activity was significantly reduced by $16.26 \%$ and $34.23 \%$, in embryos treated with, respectively, 1 or $2 \mathrm{mM} \mathrm{ACR}$, compared to the controls; CAT activity was substantially raised by $21.45 \%$ and $28.23 \%$ in embryos treated with, respectively, $1 \mathrm{mM} \mathrm{ACR}+10 \mu \mathrm{M}$ CA or $2 \mathrm{mM}$ ACR $+10 \mu \mathrm{M} \mathrm{CA}$, compare to embryos treated with 1 or $2 \mathrm{mM}$ ACR alone (Fig. 4B).

Glutathione (GSH) functions as an important antioxidant to prevent cellular damage caused by ROS. We measured GSH level in ACR-treated embryos. GSH level was noticeably decreased by $40.80 \%$ and $62.91 \%$ in embryos treated with, respectively, 1 or $2 \mathrm{mM} \mathrm{ACR}$, compared to the controls. GSH level was considerably elevated by $138.1 \%$ and $243.85 \%$ in embryos treated with, respectively, 
$1 \mathrm{mM}$ ACR $+10 \mu \mathrm{M}$ CA or $2 \mathrm{mM} \mathrm{ACR}+10 \mu \mathrm{M} \mathrm{CA}$, compared to embryos treated with 1 or $2 \mathrm{mM}$ ACR alone (Fig. 4C).

Increased ROS causes overproduction of malondialdehyde (MDA), which is one of the final products from polyunsaturated fatty acids peroxidation. MDA is widely used as a biomarker of oxidative stress (Ayala et al, 2014). The quantity of MDA was significantly raised by $9.76 \%$ and $11.88 \%$ in embryos treated with, respectively, 1 or $2 \mathrm{mM} \mathrm{ACR}$, compared to the controls. However, the quantity of MDA was substantially reduced by $9.47 \%$ and $12.53 \%$ in embryos treated with, respectively, $1 \mathrm{mM}$ ACR $+10 \mu \mathrm{M}$ CA or $2 \mathrm{mM}$ ACR $+10 \mu \mathrm{M} \mathrm{CA}$, compared to embryos treated with 1 or $2 \mathrm{mM}$ ACR alone (Fig. 4D).

\subsection{CA protected against ACR-induced photoreceptor cell death in zebrafish embryos}

288

Initially we used H\&E staining to examine morphology of retinal sections of control and treated embryos. The retinas of embryos treated with 1 or $2 \mathrm{mM}$ ACR showed a significantly decreased thickness of the photoreceptor layer (outer segments, inner segments and outer nuclear) by, respectively, $60.63 \%$ and $84.21 \%$, compared to the controls, suggesting loss of photoreceptors. By contrast, the thickness of the photoreceptor layer was considerably increased by $58.24 \%$ and $88.16 \%$, respectively, in embryos treated with $1 \mathrm{mM} A C R+10 \mu \mathrm{M}$ CA or $2 \mathrm{mM} \mathrm{ACR}+10 \mu \mathrm{M} \mathrm{CA}$, compared to embryos treated with 1 or $2 \mathrm{mM} \mathrm{ACR}$ alone (Fig. 5).

Zebrafish photoreceptors include rod cells and cone cells (red, green, blue and ultraviolet cell types) (Raghupathy et al., 2013). To determine loss of rod cells in ACR-treated embryos, we used immunostaining with 4D2 antibody (targeting rhodopsin) to visualize rod outer segments. Figure 6 shows a significant decrease of green signals (for rod outer segments) by $52.30 \%$ and $71.59 \%$, respectively, in embryos treated with 1 or $2 \mathrm{mM}$ ACR compared to the controls. By contrast, there was a markedly increased signal by $46.6 \%$ and $85.29 \%$ in embryos treated with, respectively, $1 \mathrm{mM}$ ACR $+10 \mu \mathrm{M} \mathrm{CA}$ or $2 \mathrm{mM} \mathrm{ACR}+10 \mu \mathrm{M} \mathrm{CA}$, compared to embryos treated with 1 or $2 \mathrm{mM}$ ACR alone (Fig. 6).

Additionally, we examined cone cells by immunostaining with ZRP1 antibody (labelling redgreen cones) in treated and untreated embryos. There were significantly reduced fluorescent signals of cone cells by $68.96 \%$ and $84.92 \%$ in embryos treated with, respectively, 1 or $2 \mathrm{mM} \mathrm{ACR}$, compared to 
the controls, suggesting loss of cone cells. By contrast, embryos co-exposed to $1 \mathrm{mM}$ ACR $+10 \mu \mathrm{M}$ $\mathrm{CA}$ or $2 \mathrm{mM}$ ACR $+10 \mu \mathrm{M}$ CA had a significant increase in fluorescent signals by $55.19 \%$ and $132.5 \%$, respectively, compared to embryos exposed to 1 or $2 \mathrm{mM}$ ACR alone (Fig. 7).

Given that loss of rod and cone cells in ACR-treated embryos may be due to apoptosis, we used TUNEL staining to examine cell death in the retinas of treated and untreated embryos. We found that ACR treatment resulted in a significant increase in photoreceptor death by $1166 \%$ and $2444 \%$, respectively, in embryos treated with 1 or $2 \mathrm{mM}$ ACR when compared to the controls. However cotreatment with CA led to significant reduction in cell death by $50.6 \%$ and $49.1 \%$, respectively, compared to embryos exposed to 1 or $2 \mathrm{mM}$ ACR alone (Fig. 8).

We examined whether this apoptotic death of photoreceptors is Caspase-dependent by measuring Caspase 3 expression in treated and untreated embryos by qRT-PCR (mRNA level) and by Western blotting (protein level). We found that Caspase 3 mRNA levels were markedly increased by $134.5 \%$ and $353.3 \%$ in zebrafish embryos treated with, respectively, 1 or $2 \mathrm{mM} \mathrm{ACR}$, compared to the controls. However, Caspase 3 mRNA levels were considerably reduced by $47.29 \%$ and $48.59 \%$ in embryos treated with, respectively, $1 \mathrm{mM}$ ACR $+10 \mu \mathrm{M} \mathrm{CA}$ or $2 \mathrm{mM}$ ACR $+10 \mu \mathrm{M} \mathrm{CA}$, compared to embryos treated with 1 or $2 \mathrm{mM}$ ACR alone (Fig. 9A, B). The results of Western blotting indicated that Caspase 3 protein was significantly increased by $218.6 \%$ and $351.1 \%$ in embryos treated with, respectively, 1 or $2 \mathrm{mM} \mathrm{ACR}$, compared to the controls. Co-treatment with $1 \mathrm{mM} \mathrm{ACR}+10 \mu \mathrm{M}$ CA or $2 \mathrm{mM} A C R+10 \mu \mathrm{M}$ CA resulted in a significant decrease in Caspase 3 by $65.03 \%$ and $45.96 \%$, respectively, compared to embryos solely treated with 1 or $2 \mathrm{mM}$ ACR (Fig. 9 C, D). We noticed there was a low level of Caspase 3 protein detected by Western blotting in $5 \mathrm{dpf}$ control embryo lysate. It is possible that Caspase 3 is activated in photoreceptor apoptosis in zebrafish early retinal development. Biehlmaier et al reported apoptosis in zebrafish photoreceptor cell layer was initiated at $5 \mathrm{dpf}$ and reached a maximum at $7 \mathrm{dpf}$ (Biehlmaier et al, 2001).

\section{Discussion}

Our current study used zebrafish embryos as an in vivo model to assess the toxicity of ACR on retinas and investigate the pathological mechanisms. We found that ACR caused the death of both rod and 
cone cells through Caspase-dependent apoptosis, possibly due to oxidative damage. Previous in vitro

334

studies have shown that ACR treatment resulted in significantly increased ROS generation in neural cell lines, such as the human retinal pigment epithelium cell line (ARPE-19) (Albalawi et al., 2017). In vivo studies in rodent models showed that ACR treatment caused increased ROS production in serum, lung and brain (Ghorbel et al., 2016; Lakshmi et al., 2012; Zhang et al., 2013). Our study also found that ACR-treated zebrafish embryos had a significant increase in ROS production (Fig. 2), which is consistent with the data shown by Huang et al., 2018. An increase in ROS production in both ACR-exposed cells and tissues is due to the disruption of redox homeostasis (Friedman, 2015). We found that expression of antioxidant genes (Sod1, Sod2, Catalase, Gpx1 and Nrf2) was significantly decreased in ACR-treated embryos (Fig. 3). The activities of antioxidant enzymes (SOD and GPX) and the level of GSH were also markedly decreased in ACR-treated embryos (Fig. 4). The production of MDA, a marker for lipid peroxidation and oxidative stress, was significantly increased in ACRexposed embryos (Figure 4). A recent study by Huang et al. (2018) also reported significantly decreased activity of SOD and level of GSH in zebrafish embryos. However, they found that there was no noticeable change in MDA level in ACR-treated embryos. This difference may be related to ACR-exposure time: MDA was measured at 96hpf in the study of Huang et al. while in our current study it was measured at $120 \mathrm{hpf}$; the longer exposure to ACR possibly caused MDA accumulation. In fact, decreased activities of antioxidant enzymes and level of GSH, and increased level of MDA, have been previously reported in ACR-exposed cell lines and animals (mice and rats) (Albalawi et al., 2017; Ali et al., 2014; Ghorbel et al., 2016; Kahkeshani et al., 2015; Lakshmi et al., 2012; Mehri et al., 2015; Pan et al., 2015 and 2016; Rodrigue-Ramiro et al., 2011; Zhang et al., 2013), suggesting that redox imbalance is a common feature of ACR-induced toxicity.

ACR has been reported to cause visual function defects in humans and other mammalian species. Tunnel workers exposed to ACR showed defects in light sensitivity and colour discrimination (Goffeng et al., 2008a). An electroretinography test demonstrated reduced amplitudes at $30 \mathrm{~Hz}$ flicker stimulation in these workers exposed to ACR, suggesting a dysfunction of cone cells (Goffeng et al., 2008b). Primates orally exposed to ACR had significantly decreased visual acuity and contrast sensitivity (Merigan et al., 1982, 1985), while histological analyses showed degeneration of ganglion 
cells but with sparing of the retinal inner layer and photoreceptor layer (Eskin et al., 1985, 1986), a difference from the current study that can perhaps be attributed to inter-species variation. One cow accidently exposed to ACR displayed progressive photoreceptor degeneration and optic head atrophy (Godin et al., 2000). Adult rodents exposed to ACR had significantly reduced amplitudes of ERG a and $\mathrm{b}$ waves under photopic conditions compared to untreated animals, implicating the dysfunction of cone cells (Ali et al., 2014). When pregnant rats were exposed to ACR or ACR-containing fried potato chips, the offspring showed morphological abnormalities in ganglion cells, photoreceptors and retinal pigment epithelium (RPE) cells (El-Sayyad et al., 2011; Sakr et al., 2011). However, the underlying mechanisms of visual function defects caused by ACR are poorly understood.

In our study, embryos exposed to ACR displayed significant loss of both rod and cone cells (Fig. 5-7). Our previous data showed that adult zebrafish with acute exposure to ACR ( $2 \mathrm{mM}$ for $36 \mathrm{~h}$ ) demonstrated loss of colour-preferential swimming behaviour due to death of cone photoreceptors (Jia et al., 2017). Similar to humans, zebrafish have a cone-dominant retina (Chhetri et al., 2014); loss of cone cells will result in defective colour vision, such as that presented in tunnel workers with occupational exposure to ACR (Goffeng et al. 2008a,b). Loss of photoreceptors was possibly due to apoptotic cell death, which was detected in the retinas of ACR-exposed embryos by TUNEL assay (Figure 8). Previous in vitro experiments suggested ACR-induced cell death was Caspase-dependent, since ACR-exposed cells had elevated Caspase-3 activities (Albalawi et al., 2017; Pan et al., 2016; Rodriguez-Ramiro et al., 2011; Sumizawa and Igisu, 2007). A recent study showed that ACR exposure led to endoplasmic reticulum (ER) stress-dependent apoptotic cell death in SH-SY5Y cells and in the brain of zebrafish larvae at 7dpf mediated by the eIF2 $\alpha$-ATF4-CHOP signalling pathway (Komoike and Matsuoka, 2016). Our data showed that Caspase 3 was markedly increased at mRNA and protein levels in ACR-exposed embryos (Fig.), suggesting the apoptotic photoreceptor death is possibly Caspase 3-dependent, although we cannot exclude the possibility that other cell death pathways may be involved in ACR-induced photoreceptor loss.

Previous studies reported that CA protected RPE (ARPE-19) cells and photoreceptor (661W) cells against $\mathrm{H}_{2} \mathrm{O}_{2}$-induced oxidative damage in vitro and protected rodent photoreceptor cells against lightinduced damage (Rezaie et al., 2012; Nagar et al., 2017). CA also demonstrated a protective effect on 
photoreceptor cell death in a retinitis pigmentosa (RP) mouse model (rd10) such that CA treatment resulted in a significant decrease in rod photoreceptor death (Kang et al., 2016). These neuroprotective effects of CA are thought to be through inhibition of oxidative stress and ER stress. Our recent data showed that CA exposure prevented RPE cell death from ACR-induced oxidative damage. RPE cells exposed to ACR had significantly decreased expression of antioxidant genes, while CA treatment reversed ACR-induced toxic effects (Albalawi et al., 2017). NRF2 is involved in protection of retinal cells from oxidative damage through up-regulation of endogenous antioxidants and phase II detoxifying enzymes (Rezaie et al., 2012; Alhasani et al., 2018). Loss of NRF2 in mice caused age-dependent RPE deterioration (Zhao et al., 2011). Overexpression of NRF2 slowed photoreceptor cell death in retinal degeneration mouse models (Xiong et al., 2015). CA treatment resulted in a marked increase of retinal NRF2 in light-induced damage mouse model and in RP mouse model (Kang et al., 2016; Nagar et al., 2017). ACR exposure also caused down-regulation of NRF2 expression in retinal cells, while CA treatment reversed the effect (Albalawi et al., 2017). Our current study also showed that CA treatment protected photoreceptor cells from ACR-induced oxidative damage (Fig. 6,7), possibly through inhibition of oxidative stress mediated by the NRF signalling pathway (Fig. 3E).

\section{Conclusion}

This study has investigated ACR-induced toxicity and evaluated protective effects of CA on photoreceptor death in zebrafish embryos. ACR treatment caused overproduction of ROS and MDA, reduced expression of antioxidant genes and activities of antioxidant enzymes, and increased photoreceptor cell death in zebrafish embryos. Our study demonstrates for the first time that exposure to $\mathrm{CA}$ has protective effects against ACR-induced toxicity in the retina and suggests that treatment with CA may have neuroprotective potential in humans exposed to ACR.

\section{Acknowledgement}

AA and RHA are suported by PhD scholarships from Saudi Arabia Government. We would like to thank the Rosetrees Trust (M160, M160-F1, M160-F2), National Eye Research Centre (SCIAD063, SAC037), the Glasgow Children's Hospital Charity (YRSS/PSG/2014/06) and the Visual Research 
417 Trust for supporting this work. This project was also supported by King Saud University, the Vice

418 Deanship of Scientific Research Chairs. The maintenance of GCU Zebrafsh Facility was funded by

419 the EU INTERREG NEW noPILLS programme.

\section{References}

421 Albalawi. A., Alhasani, R.H.A., Biswas, L., Reilly, J., Shu, X., 2017. Protective effect of carnosic

422 acid against acrylamide-induced toxicity in RPE cells. Food Chem. Toxicol. 108(Pt B), 543-553.

423 Alhasani, R.H., Biswas, L., Tohari, A.M., Zhou, X., Reilly, J., He, J.F., Shu, X., 2018. Gypenosides

424 protect retinal pigment epithelium cells from oxidative stress. Food Chem. Toxicol. 112, 76-85.

425 Ali, M.A., Aly, E.M., Elawady, A.I., 2014. Effectiveness of selenium on acrylamide toxicity to retina.

426 Int. J. Ophthalmol. 7, 614-620.

427 Ayala, A., Muñoz, M.F., Argüelles, S., 2014. Lipid peroxidation: production, metabolism, and 428 signaling mechanisms of malondialdehyde and 4-hydroxy-2-nonenal. Oxid. Med. Cell Longev. $4292014,360438$.

430 Bahri, S., Jameleddine, S., Shlyonsky, V., 2016. Relevance of carnosic acid to the treatment of several 431 health disorders: molecular targets and mechanisms. Biomed. Pharmacother. 84, 569-582.

432 Biehlmaier, O., Neuhauss, S.C., Kohler, K., 2001. Onset and time course of apoptosis in the 433 developing zebrafish retina. Cell Tissue Res. 306, 199-207.

434 Birtić, S., Dussort, P., Pierre, F.X., Bily, A.C., Roller, M., 2015. Carnosic acid. Phytochemistry 115, $4359-19$.

436 Dybing, E., Farmer, P.B., Andersen, M., Fennell, T.R., Lalljie, S.P., Müller, D.J., Olin, S., Petersen, B.J., Schlatter, J., Scholz, G., Scimeca, J.A., Slimani, N., Tornqvist, M., Tuijtelaars, S., Verger, P., 2005. Human exposure and internal dose assessments of acrylamide in food. Food Chem. Toxicol. 43, $365-410$.

Chhetri, J., Jacobson, G., Gueven, N., 2014. Zebrafish—on the move towards ophthalmological research. Eye 28, 367-380.

EFSA, 2015. Scientific opinion on acrylamide in food. EFSA. J. 13, 4104. on the development of retina in albino rats. Asian Pac. J. Trop. Biomed. 1, 253-260. 

macaque visual system. II. Retinogeniculate morphology. Invest. Ophthalmol. Vis. Sci. 26, 317-329. Eskin, T.A., Merigan, W.H., 1986. Selective acrylamide-induced degeneration of color opponent ganglion cells in macaques. Brain Res. 378, 379-384.

Exon, J.H., 2006. A Review of the Toxicology of Acrylamide, J. Toxicol. Environ. Health B Crit. Rev. 9, 397-412.

Friedman, M., 2015. Acrylamide: inhibition of formation in processed food and mitigation of toxicity in cells, animals, and humans. Food Funct. 6, 1752-1772.

Ghorbel, I., Chaâbane, M., Boudawara, O., Kamoun, N.G., Boudawara, T., Zeghal, N., 2016. Dietary unsaponifiable fraction of extra virgin olive oil supplementation attenuates lung injury and DNA damage of rats co-exposed to aluminum and acrylamide. Environ. Sci. Pollut. Res. Int. 23, $19397-$ 19408.

Godin, A.C., Dubielzig, R.R., Giuliano, E., Ekesten, B., 2000. Retinal and optic nerve degeneration in cattle after accidental acrylamide intoxication. Vet. Ophthalmol. 3, 235-239.

Goffeng, L.O., Kjuus, H., Heier, M.S., Alvestrand, M., Ulvestad, B., Skaug, V., 2008a. Colour vision and light sensitivity in tunnel workers previously exposed to acrylamide and N-methylolacrylamide containing grouting agents. Neurotoxicology 29, 31-39. conduction, visual evoked responses and electroretinography in tunnel workers previously exposed to acrylamide and N-methylolacrylamide containing grouting agents. Neurotoxicol. Teratol. 30, 186194. investigating chemical toxicity. Toxicol. Sci. 86, 6-19. postmitotic cells. Dev. Biol. 207, 309-321. 

oxidative stress and cardiovascular toxicity in zebrafish embryos. J. Hazard Mater. 347, 451-460. Jia, L., Raghupathy, R.K., Albalawi, A., Zhao, Z., Reilly, J., Xiao, Q., Shu, X., 2017. A colour preference technique to evaluate acrylamide-induced toxicity in zebrafish. Comp. Biochem. Physiol. C Toxicol. Pharmacol. 199, 11-19.

Kahkeshani, N., Saeidnia, S., Abdollahi, M., 2015. Role of antioxidants and phytochemicals on acrylamide mitigation from food and reducing its toxicity. J. Food Sci. Technol. 52, 3169-3186 Kang, K., Tarchick, M.J., Yu, X., Beight, C., Bu, P., Yu, M., 2016. Carnosic acid slows photoreceptor degeneration in the Pde6b(rd10) mouse model of retinitis pigmentosa. Sci. Rep. 6, 22632. Komoike, Y., Matsuoka, M., 2016. Endoplasmic reticulum stress-mediated neuronal apoptosis by acrylamide exposure. Toxicol. Appl. Pharmacol. 310, 68-77.

Ameliorating effect of fish oil on acrylamide induced oxidative stress and neuronal apoptosis in cerebral cortex. Neurochem. Res. 37, 1859-1867. McGrath, P., Li, C.Q., 2008. Zebrafish: a predictive model for assessing drug-induced toxicity. Drug Discov. Today 13, 394-401. reduced acrylamide-induced neurotoxicity in Wistar rat through inhibition of oxidative stress. Iran. J. Basic Med. Sci. 18, 902-908

Merigan, W.H., Barkdoll, E., Maurissen, J.P., 1982. Acrylamide-induced visual impairment in primates. Toxicol. Appl. Pharmacol. 62, 342-345. on the macaque visual system. I. Psychophysics and electrophysiology. Invest. Ophthalmol. Vis. Sci. $26,309-316$. Moore, J., Yousef, M., Tsiani, E., 2016. Anticancer effects of rosemary (Rosmarinus officinalis L.) extract and rosemary extract polyphenols. Nutrients 8, pii: E731. 
downregulates the NRF2 pathway and renders photoreceptors susceptible to light-induced oxidative stress. Proc. Natl. Acad. Sci. U. S. A. 114, E4048-E4056.

500 Pan, X., Zhu, L., Lu, H., Wang, D., Lu, Q., Yan, H., 2015. Melatonin attenuates oxidative damage 501 induced by acrylamide in vitro and in vivo. Oxid. Med. Cell Longev. 2015, 703709. Pan, X., Yan, D., Wang, D., Wu, X., Zhao, W., Lu, Q., Yan, H., 2016. Mitochondrionmediated apoptosis induced by acrylamide is regulated by a balance between Nrf2 antioxidant and MAPK signaling pathways in PC12 cells. Mol. Neurobiol, 54, 4781-4794. Raghupathy, R.K., McCulloch, D.L., Akhtar, S., Al-mubrad, T.M., Shu, X., 2013. Zebrafish model for the genetic basis of X-linked retinitis pigmentosa. Zebrafish 10, 62-69. Rezaie, T., McKercher, S.R., Kosaka, K., Seki, M., Wheeler, L., Viswanath, V., Chun, T., Joshi, R., Valencia, M., Sasaki, S., Tozawa, T., Satoh, T., Lipton, S.A., 2012. Protective effect of carnosic acid, a pro-electrophilic compound, in models of oxidative stress and light-induced retinal degeneration. Invest. Ophthalmol. Vis. Sci. 53, 7847-7854. Rodríguez-Ramiro, I., Ramos, S., Bravo, L., Goya, L., Martín, M.A., 2011. Procyanidin B2 and a cocoa polyphenolic extract inhibit acrylamide-induced apoptosis in human Caco-2 cells by preventing oxidative stress and activation of JNK pathway. J. Nutr. Biochem. 22, 1186-1194. Sakr, S.A., Badawy, G.M., El-sayyad, H.I., Afify, H.S., 2011. Adverse effects of acrylamide on the developing retina of albino rats, J. Basic. Appl. Sci. Res. 1, 706-712.

Schmitt, E.A., Dowling, J.E., 1999. Early retinal development in the zebrafish, Danio rerio: light and electron microscopic analyses. J. Comp. Neurol. 404, 515-536.

Zebrafish Rpgr is required for normal retinal development and plays a role in dynein-based retrograde transport processes. Hum. Mol. Genet. 19, 657-670. Carcinogens" reported in cigarette mainstream smoke. Food Chem. Toxicol. 38, 371-383. $81,279-282$.

Tareke, E., Rydberg, P., Karlsson, P., Eriksson, S., Törnqvist, M., 2002. Analysis of acrylamide, a 
527 Tohari, A.M., Zhou, X., Shu, X., 2016. Protection against oxidative stress by vitamin D in cone cells.

528 Cell Biochem. Funct. 34, 82-94.

529

530

531

532

533

534

535

536

537

538

539

540

541

542

543

544

545

546

547

548

549

550

551

552

553

carcinogen formed in heated foodstuffs. J. Agric. Food Chem. 50, 4998-5006.

Xiong, W., MacColl Garfinkel, A.E., Li, Y., Benowitz, L.I., Cepko, C.L., 2015. NRF2 promotes neuronal survival in neurodegeneration and acute nerve damage. J. Clin. Invest. 125, 1433-1445.

Zhang, L., Wang, E., Chen, F., Yan, H., Yuan, Y., 2013. Potential protective effects of oral administration of allicin on acrylamide-induced toxicity in male mice. Food Funct. 4, 1229-1236.

Zhang, P., Pan, H., Wang, J., Liu, X., Hu, X., 2014. Telomerase activity-independent function of telomerase reverse transcriptase is involved in acrylamide-induced neuron damage. Biotech.

Histochem. 89, 327-335.

Zhang, X., Hong, Q., Yang, L., Zhang, M., Guo, X., Chi, X., Tong, M., 2015. PCB1254 exposure contributes to the abnormalities of optomotor responses and influence of the photoreceptor cell development in zebrafish larvae. Ecotoxicol. Environ. Saf. 118, 133-138.

Zhao, Z., Chen, Y., Wang, J., Sternberg, P., Freeman, M.L., Grossniklaus, H.E., Cai, J., 2011. Agerelated retinopathy in NRF2-deficient mice. PLoS One 6, e19456.

Zyzak, D.V., Sanders, R.A., Stojanovic, M., Tallmadge, D.H., Eberhart, B.L., Ewald, D.K., Gruber, D.C., Morsch, T.R., Strothers, M.A., Rizzi, G.P., Villagran, M.D., 2003. Acrylamide formation mechanisms in heated foods. J. Agric. Food Chem. 51, 4782-4787.

4

.


555 Figure 1 Evaluation of toxic effects of acrylamide (ACR) and carnosic acid (CA) on zebrafish embryos. (A) Zebrafish embryos were exposed from $6 \mathrm{hpf}$ to $72 \mathrm{hpf}$ to ACR at different concentrations. ACR treatment at $3 \mathrm{mM}$ or higher concentration caused significantly increased mortality. ACR treatment at $1 \mathrm{mM}$ or higher caused a marked decrease in hatching and heart rate. (B) Zebrafish embryos were exposed to $\mathrm{CA}$ at different concentration. CA treatment at $30 \mu \mathrm{M}$ or higher concentration resulted in a significant increase in mortality and a significant decrease in hatching and heart rate. There were no significant differences observed in embryos treated with CA at 10 or $20 \mu \mathrm{M}$ when compared to the controls. (C) Co-treatment with CA reversed ACR-induced toxicity. Hatching and heart rate were significantly increased in embryos co-treated with CA and ACR compared to embryos treated with ACR alone. UT: untreated control. NS, no significance; ${ }^{*} \mathrm{p}<0.05 ;{ }^{*} \mathrm{p}<0.01$; $* * * \mathrm{p}<0.001 ; * * * * \mathrm{p}<0.0001$

Figure 2 ACR exposure from 6-120 hpf induced increased production of ROS in zebrafish embryos, while co-treatment with CA from 6-120 hpf supressed this ACR-induced ROS production. ROS was measured as described in Materials and methods. UT: untreated control. ${ }^{*} \mathrm{p} p<0.01 ;{ }^{*} * \mathrm{p}<0.001$; $* * * * \mathrm{p}<0.0001$

Figure 3 ACR exposure from 6-120 hpf caused decreased expression of antioxidant genes in zebrafish embryos, while co-treatment with CA from 6-120 hpf significantly enhanced the expression of these antioxidant genes. Expression of Sod1 (A), Sod2 (B), Catalase (C), Nrf2 (D) and Gpx1 (E) was measured by qRT-PCR and normalized to the housekeeping gene, $\beta$-actin. UT: untreated control. $* \mathrm{p}<0.05 ; * * \mathrm{p}<0.01 ; * * * * \mathrm{p}<0.0001$

Figure 4 ACR exposure from 6-120 hpf resulted in significantly decreased activities in zebrafish embryos of Sod (A) and catalase (B), decreased level of GSH (C), and increased level of MDA (D). Co-treatment with CA reversed the ACR-induced effects. SOD and catalase (CAT) activities, GSH and MDA levels were measured as described in Materials and methods. UT: untreated control. ${ }^{*} \mathrm{p}<0$. $05 ; * * \mathrm{p}<0.01 ; * * * \mathrm{p}<0.001 ; * * * * \mathrm{p}<0.0001$

580 Figure 5 (A) Haemotoxylin and Eosin stained retinal sections of zebrafish embryos treated from 6120hpf with $1 \mathrm{mM}$ ACR, $2 \mathrm{mM}$ ACR, $1 \mathrm{mM}$ ACR $+10 \mu \mathrm{M} \mathrm{CA}$, or $2 \mathrm{mM}$ ACR $+10 \mu \mathrm{M}$ CA. Scale bar, 
582

583

584

585

586

587

588

589

590

591

592

593

594

595

596

597

598

599

600

601

602

603

604

605

606

607

608

609

$20 \mu \mathrm{m}$. GCL, ganglion cell layer; INL, inner nuclear layer; ONL, outer nuclear layer; RPE, retinal pigment epithelium. (B) The thickness of the photoreceptor layer of untreated (UT) and treated embryos was measured using Image J software. For each condition the data were collected by measuring six images from three eyes $* \mathrm{p}<0.05 ; * * * \mathrm{p}<0.001 ; * * * * \mathrm{p}<0.0001$.

Figure 6 (A) Rod cells were detected by immunostaining with anti-rhodopsin (4D2) antibody (targeting rod outer segments) in retinal sections of zebrafish embryos treated from 6-120hpf with $1 \mathrm{mM}$ ACR, $2 \mathrm{mM}$ ACR, $1 \mathrm{mM} \mathrm{ACR}+10 \mu \mathrm{M} \mathrm{CA}$, or $2 \mathrm{mM} \mathrm{ACR}+10 \mu \mathrm{M} \mathrm{CA}$. (B) CA treatment significantly counteracted the reduction in fluorescence intensity caused by ACR exposure. Six images were taken from control and treated retinal sections; fluorescence intensity of rod outer segments in individual images was quantified using Image $\mathrm{J}$ software. ${ }^{* *} \mathrm{p}<0.01 ; * * * * \mathrm{p}<0.0001$.

Figure 7 (A) Cone cells were detected by immunostaining with ZPR-1 antibody in retinal sections of zebrafish embryos treated from 6-120hpf with 1mM ACR, $2 \mathrm{mM} \mathrm{ACR,} 1 \mathrm{mM}$ ACR $+10 \mu \mathrm{M}$ CA, or $2 \mathrm{mM}$ ACR $+10 \mu \mathrm{M}$ CA. (B) CA treatment significantly counteracted the reduction in fluorescence intensity caused by ACR exposure. Six images were taken from control and treated retinal sections; fluorescence intensity of cone cells in individual images was quantified using Image $J$ software. $\left.{ }^{*} \mathrm{p}<0.05 ; * * * \mathrm{p}<0.001 ; * * * \mathrm{p}<0.0001\right)$.

Figure 8 Significant increases of apoptosis in acrylamide-exposed zebrafish embryos photoreceptor cells were detected by a TUNEL assay. (A) Nuclei of apoptotic photoreceptor cells are stained in green. Retinal sections of embryos exposed from 6-12-hpf to 1mM ACR, 2mM ACR, $1 \mathrm{mM} \mathrm{ACR}+$ $10 \mu \mathrm{M} \mathrm{CA}$, or $2 \mathrm{mM}$ ACR $+10 \mu \mathrm{M} \mathrm{CA}$ were stained with TUNEL reagents and DAPI to detect apoptotic cells. (B) Quantification of apoptotic cells showing CA treatment resulted in a significant decrease in the cell death induced by ACR. The data were collected by counting TUNEL positive cells from 6 images of retinal sections from control and treated zebrafish embryos. ${ }^{*} \mathrm{p}<0.05$; $* * * \mathrm{p}<0.001 ; * * * * \mathrm{p}<0.0001$

Figure 9 ACR-exposed embryos exhibited a significant increase in Caspase 3 at mRNA and protein levels, while co-treatment with CA reversed these ACR-induced effects. Zebrafish embryos were treated from 6 to 120 hpf with $1 \mathrm{mM} \mathrm{ACR}, 2 \mathrm{mM}$ ACR, $1 \mathrm{mM} \mathrm{ACR}+10 \mu \mathrm{M} \mathrm{CA}$, or $2 \mathrm{mM} \mathrm{ACR}+10$ $\mu \mathrm{M}$ CA. The expression of Caspase3 was determined by qRT-PCR and Western blotting. (A) Agarose 
611 the housekeeping gene $\beta$-actin. (C) Western blotting gel image of Caspase 3 protein. (D)

612 Quantification of Caspase 3 protein in untreated and treated zebrafish embryos normalized to

613 GAPDH. UT: untreated control. ${ }^{*} \mathrm{p}<0.05 ;{ }^{* *} \mathrm{p}<0.01 ; * * * \mathrm{p}<0.001 ; * * * * \mathrm{p}<0.0001$.

614

\section{Supplementary data}

616 Figure S1 Curved body (A) and cardiac edema (B) were present in zebrafish embryos exposed to

617 ACR at $2 \mathrm{mM}$ or higher concentration.

618

619 Table S1 Sequences of primers used in qRT-PCR

\begin{tabular}{|c|c|c|c|}
\hline Gene & Primer sequence & $\begin{array}{l}\text { Annealing } \\
\text { temperature }\left({ }^{\circ} \mathrm{C}\right)\end{array}$ & $\begin{array}{l}\text { Amplicon size in } \\
\text { base pairs }\end{array}$ \\
\hline$\beta$-actin & $\begin{array}{l}\mathrm{F}=\text { ACATCCGTAAGGACCTG } \\
\mathrm{R}=\text { GGTCGTTCGTTTGAATCTC }\end{array}$ & 50.95 & 319 \\
\hline Sod1 & $\begin{array}{l}\mathrm{F}=\text { CGCATGTTCCCAGACATCTA } \\
\mathrm{R}=\text { GAGCGGAAGATTGAGGATTG }\end{array}$ & 53.9 & 100 \\
\hline Sod2 & $\begin{array}{l}\mathrm{F}=\text { CTAGCCCGCTGACATTACATC } \\
\mathrm{R}=\text { TTGCCCACATAGAAATGCAC }\end{array}$ & 54.5 & 101 \\
\hline CAT & $\begin{array}{l}\mathrm{F}=\text { TGAGGCTGGGTCATCAGATA } \\
\mathrm{R}=\text { AAAGACGGAAACAGAAGCGT }\end{array}$ & 54.95 & 138 \\
\hline Nrf2 & $\begin{array}{l}\mathrm{F}=\text { GAGCGGGAGAAATCACACAGAATG } \\
\mathrm{R}=\text { CAGGAGCTGCATGCACTCATCG }\end{array}$ & 59.25 & 85 \\
\hline Gpx1 & $\begin{array}{l}\mathrm{F}=\text { AGGCACAACAGTCAGGGATT } \\
\mathrm{R}=\text { CAGGAACGCAAACAGAGGG }\end{array}$ & 56.45 & 241 \\
\hline Caspase 3 & $\begin{array}{l}\mathrm{F}=\text { TAGTGTGTGTGTTGCTCAGTC } \\
\mathrm{R}=\text { CTCGACAAGCCTGAATAAAG }\end{array}$ & 56.16 & 153 \\
\hline
\end{tabular}

F: forward primer; R: reverse primer 
Figure 1
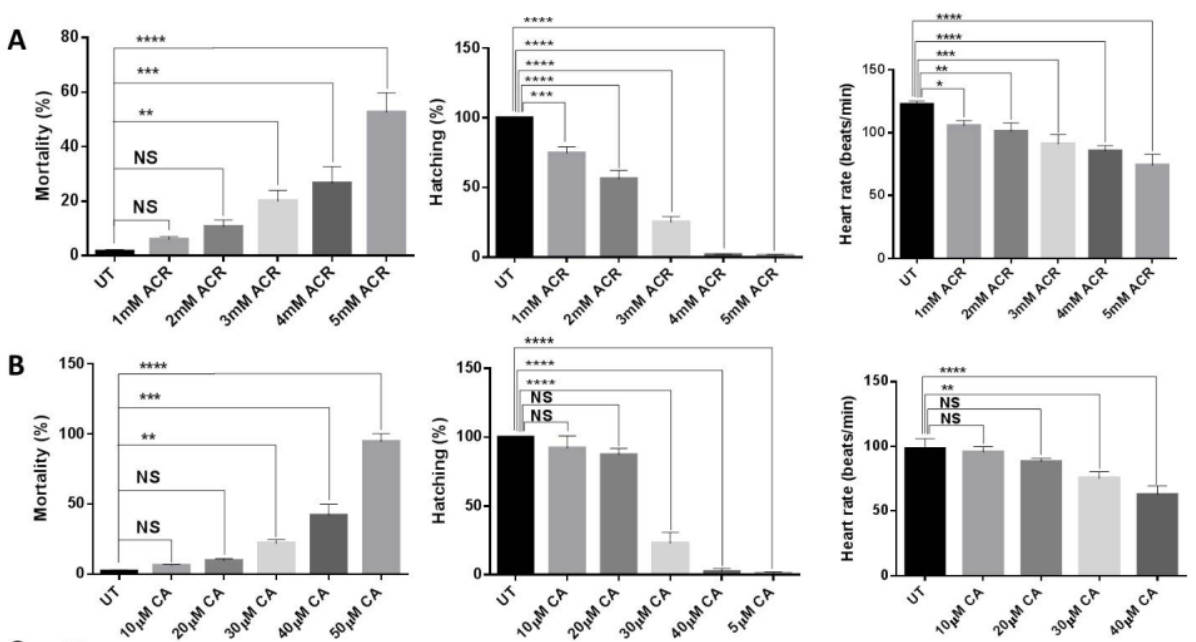

625

C
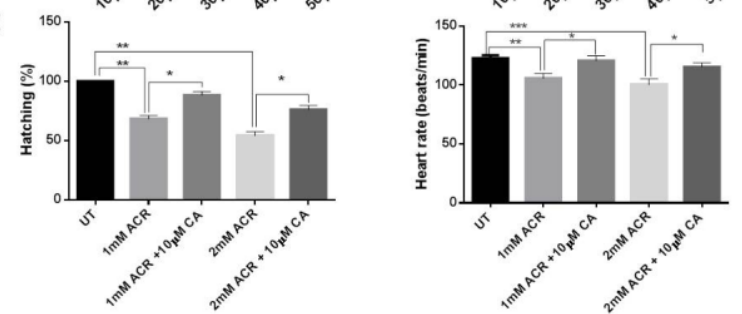

626

627

Figure 2

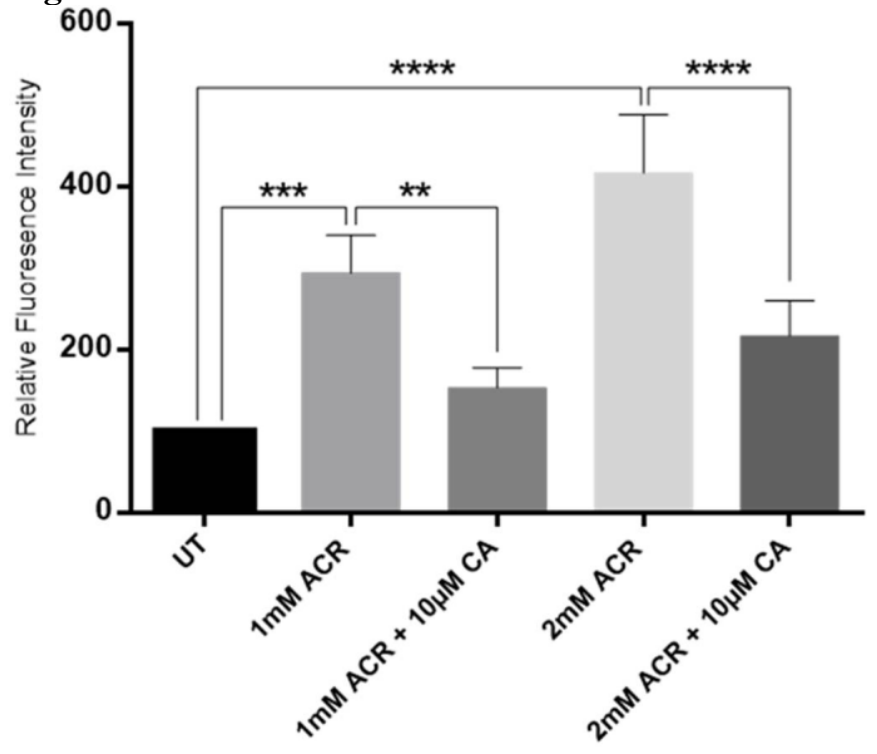


$642 \quad$ Figure 3

A

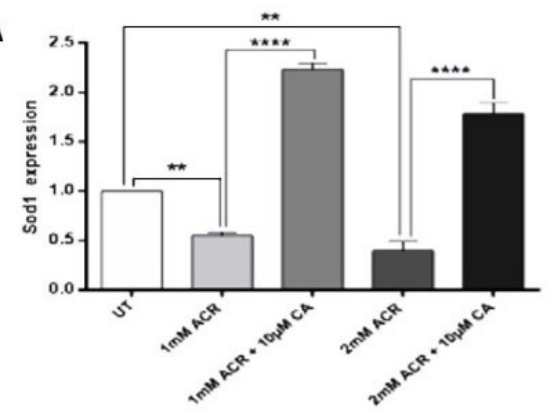

C

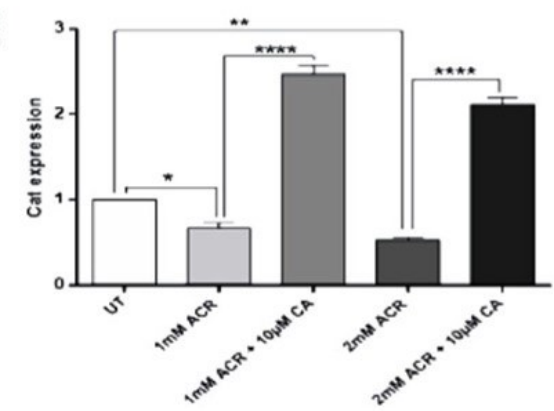

E

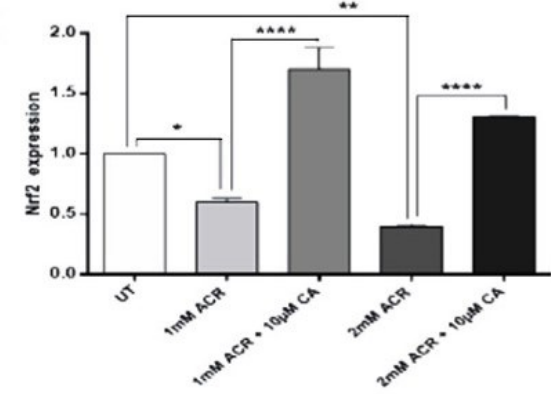

B

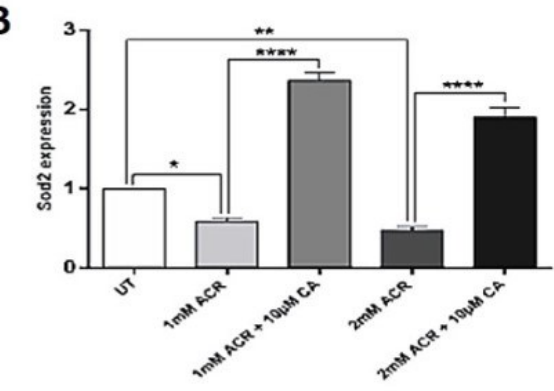

D

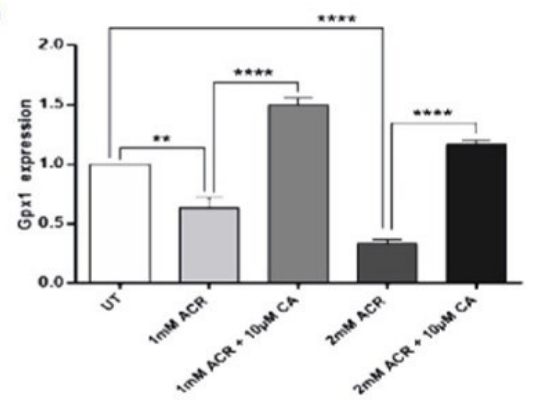

Figure 4
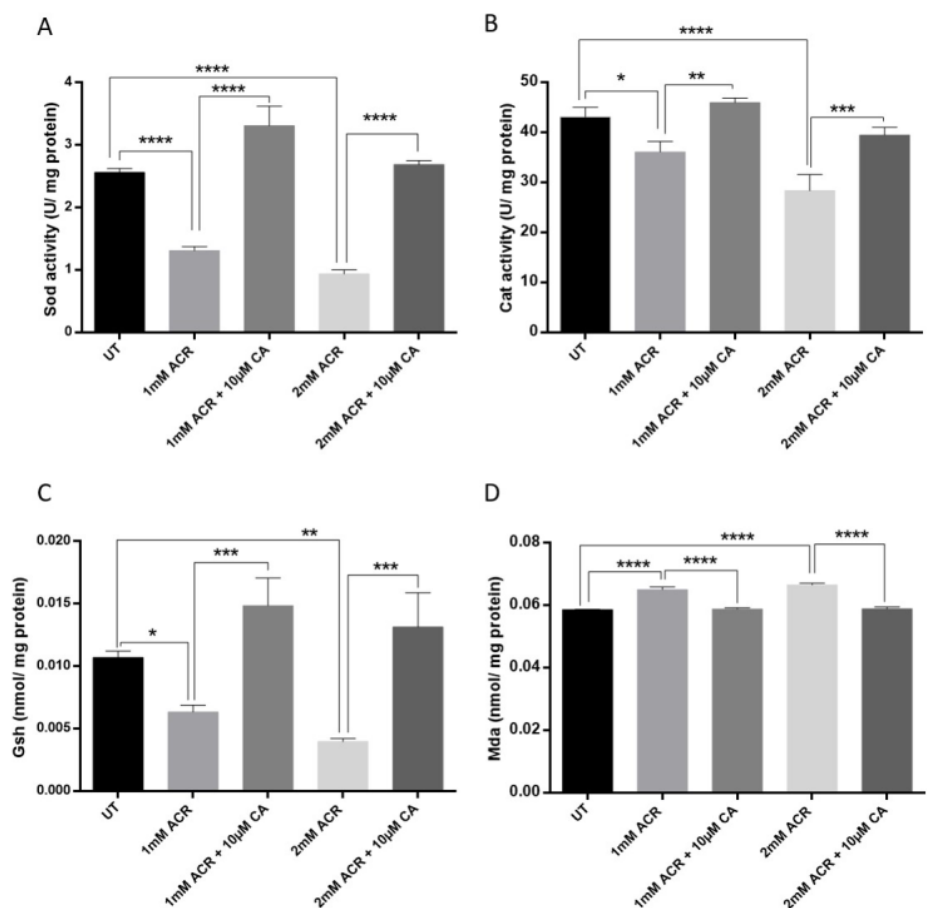

D

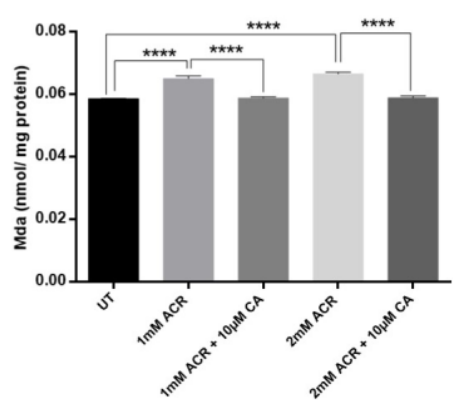


A UT

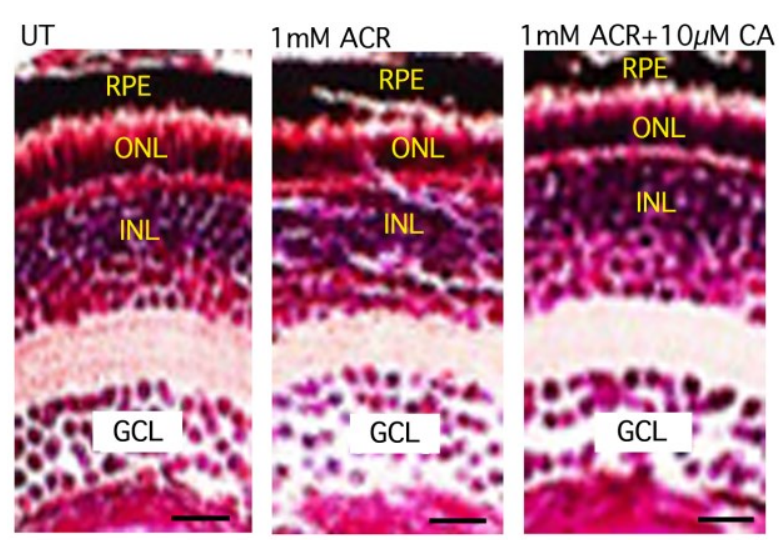

2mM ACR

$2 \mathrm{mM} \mathrm{ACR}+10 \mu \mathrm{M} \mathrm{CA}$
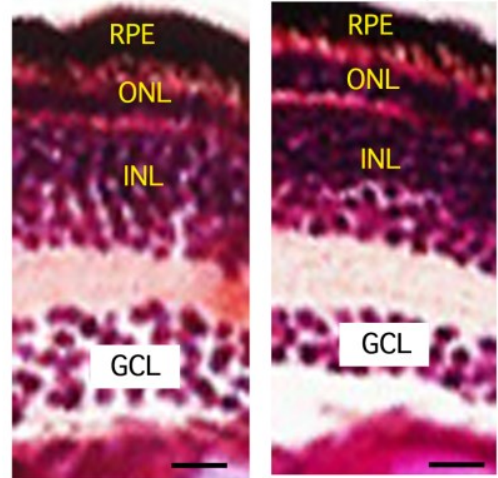

$\mathrm{BSCL}$

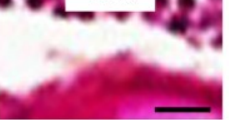

B

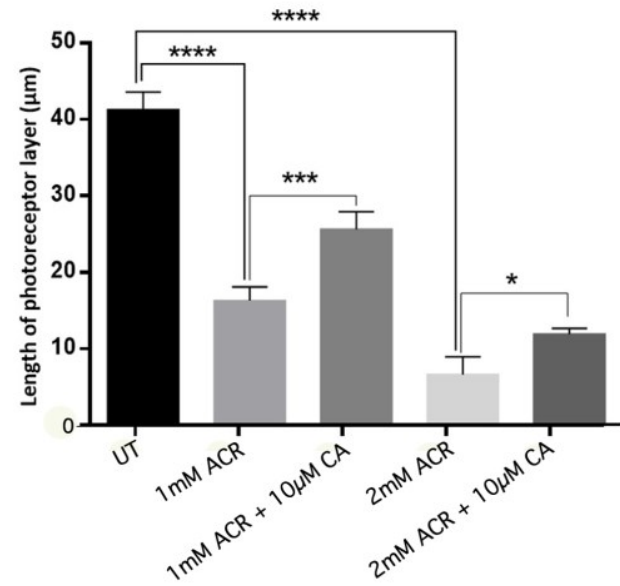


Figure 6

A
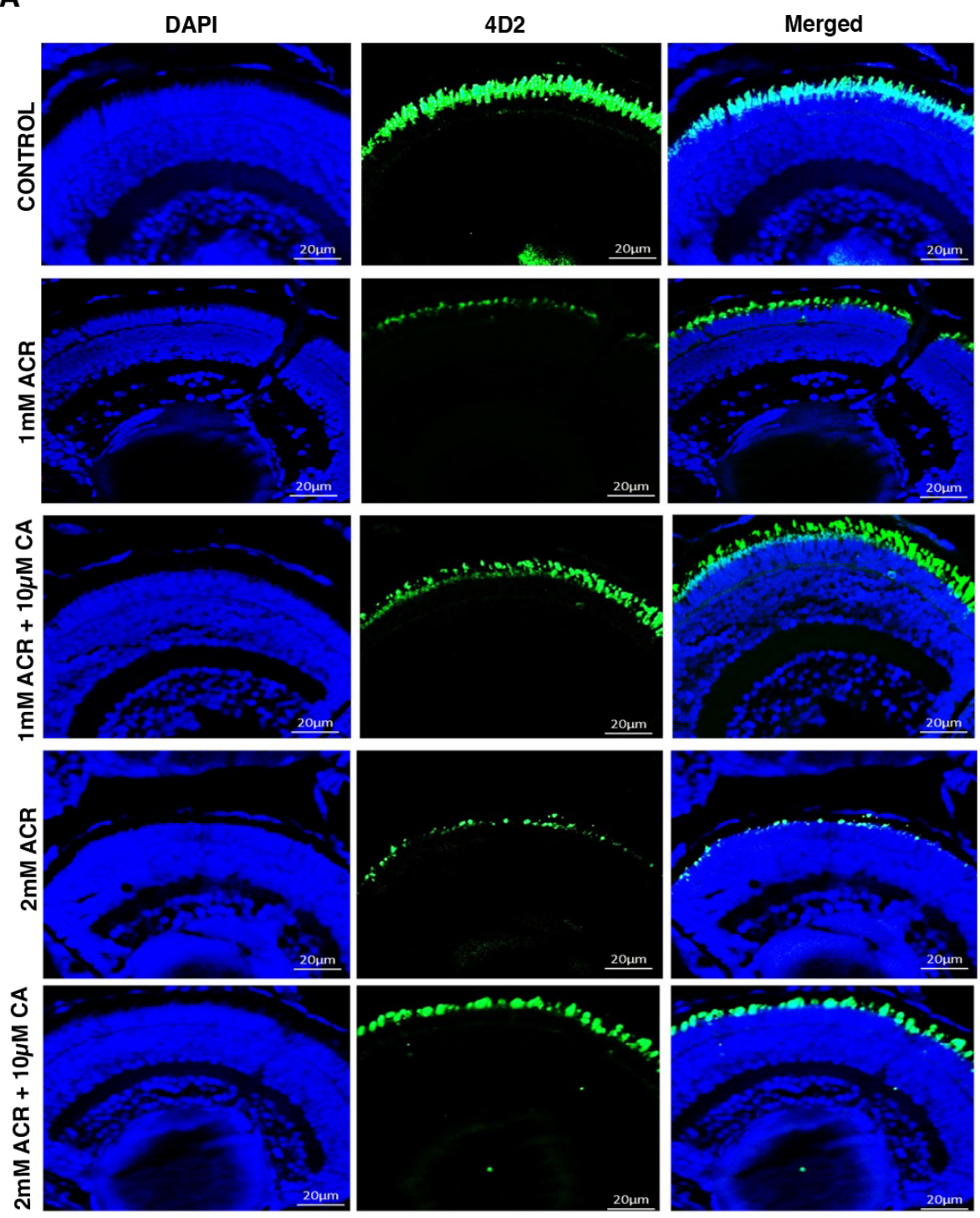

B

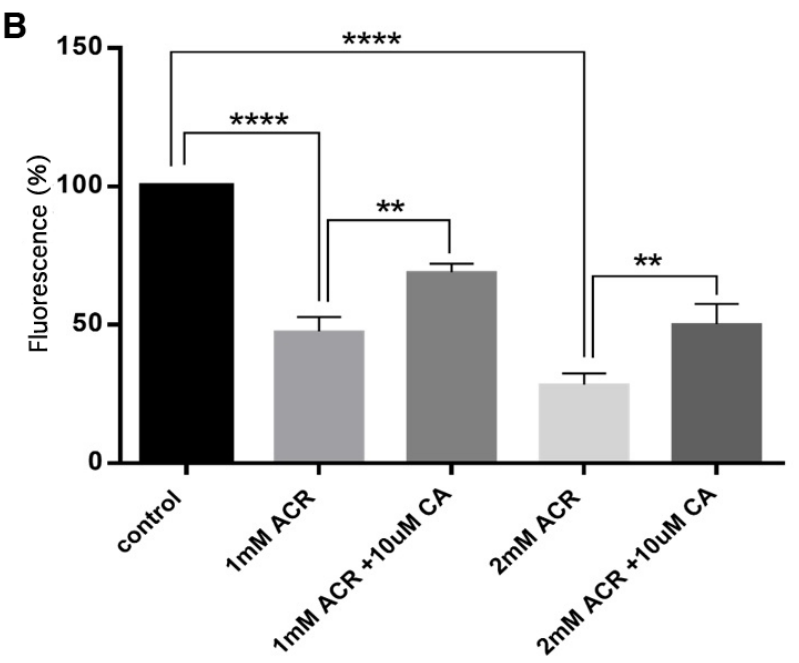


Figure 7

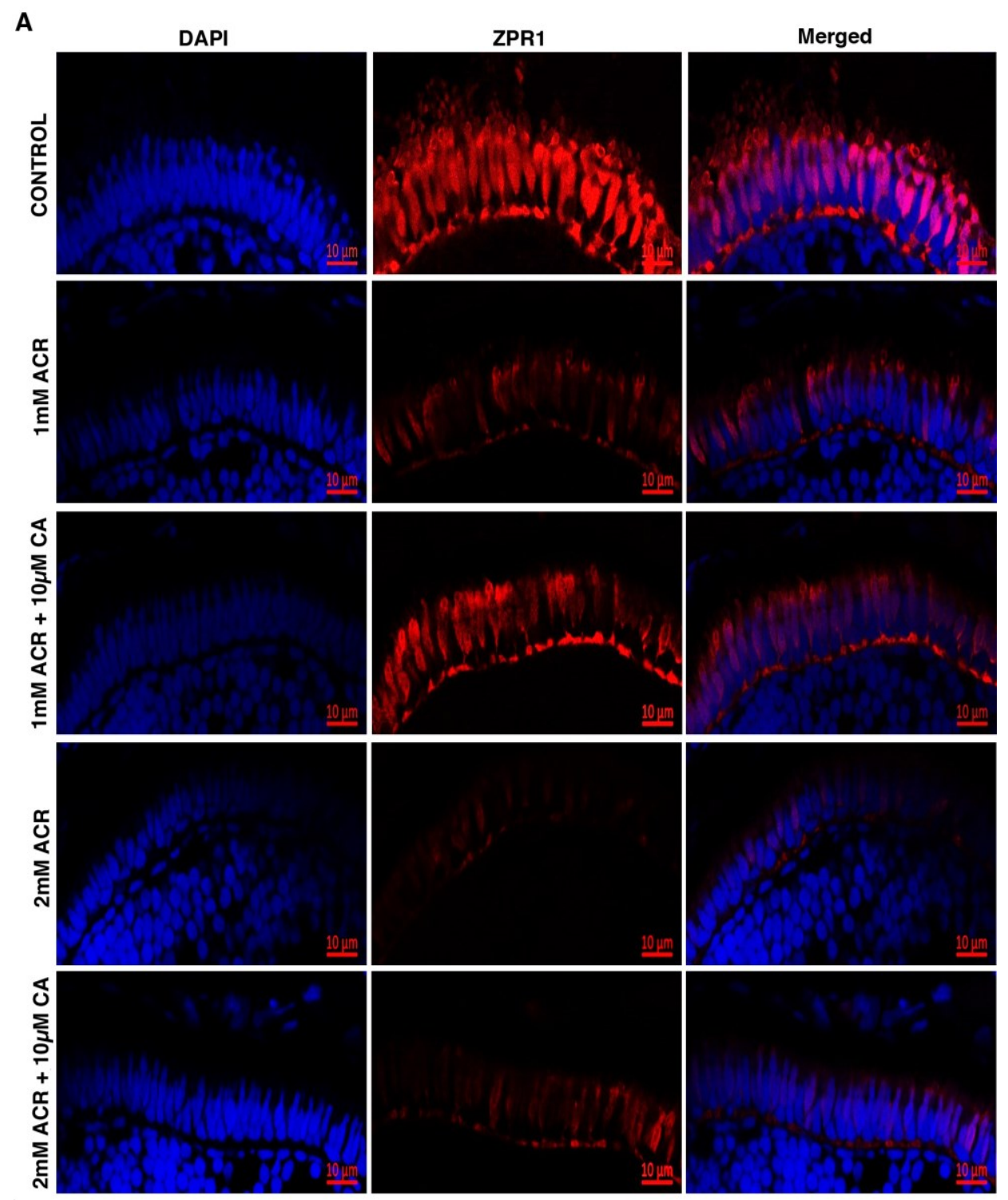

B

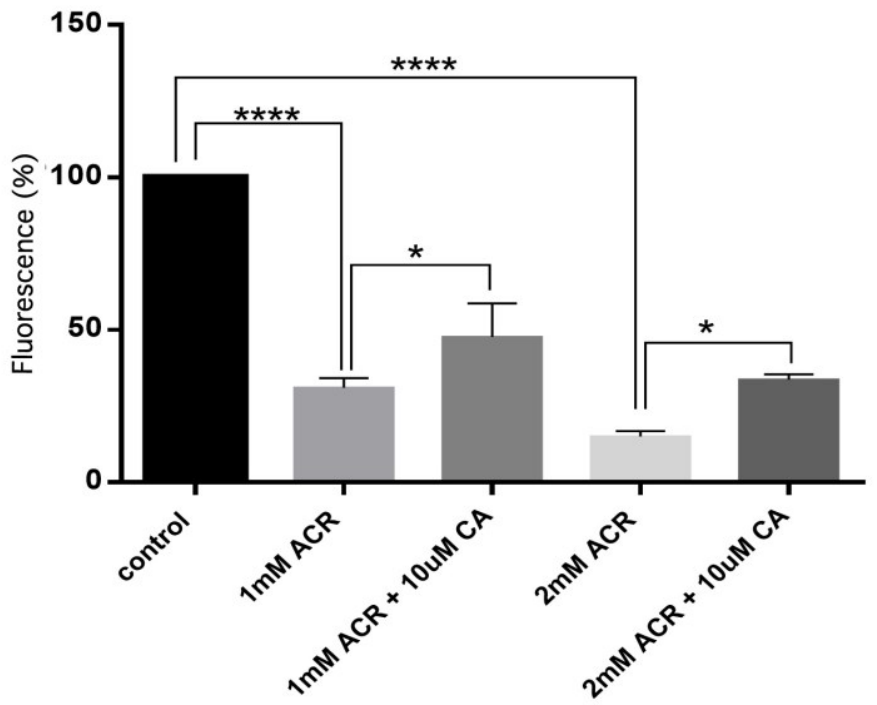


$662 \quad$ Figure 8

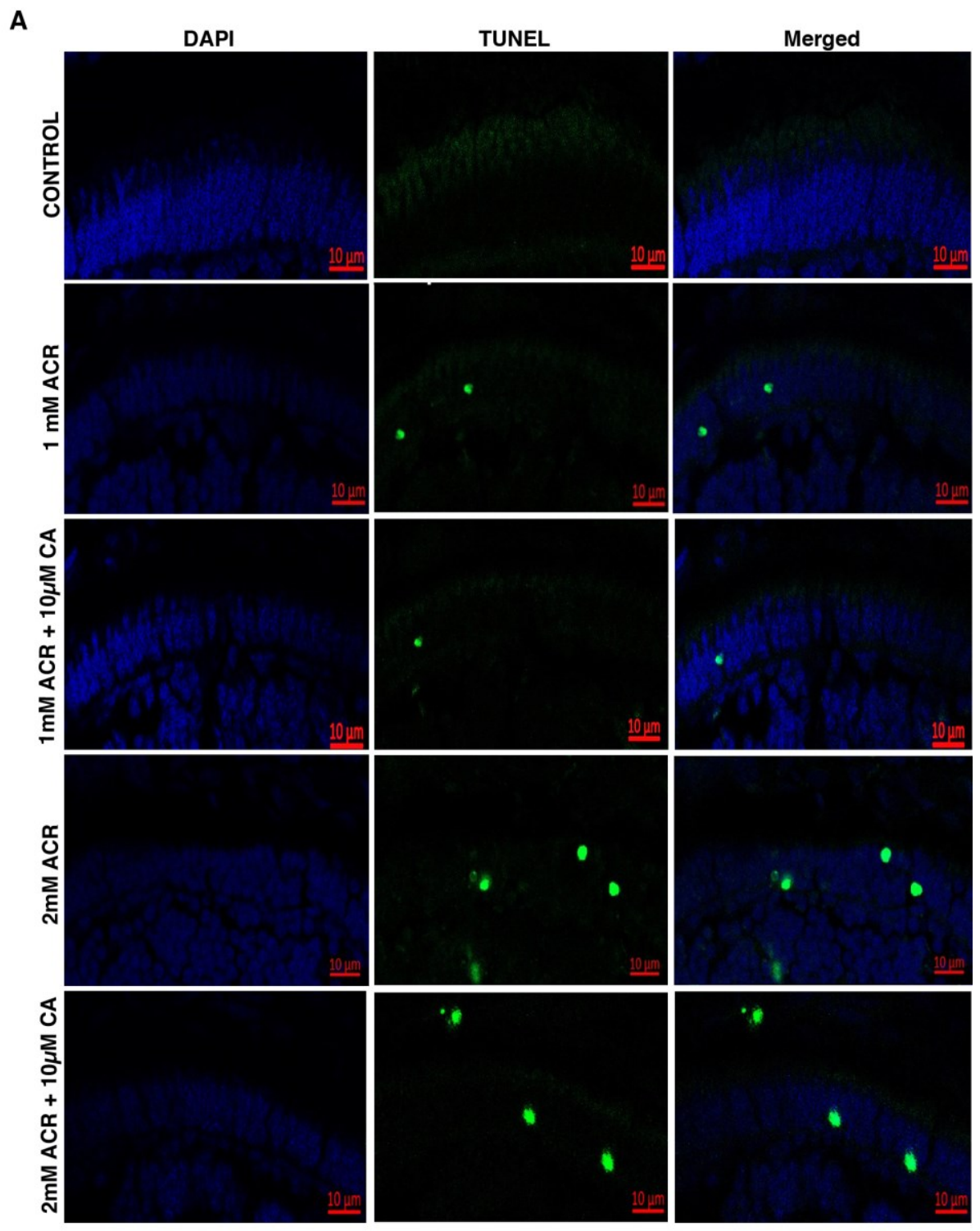

B

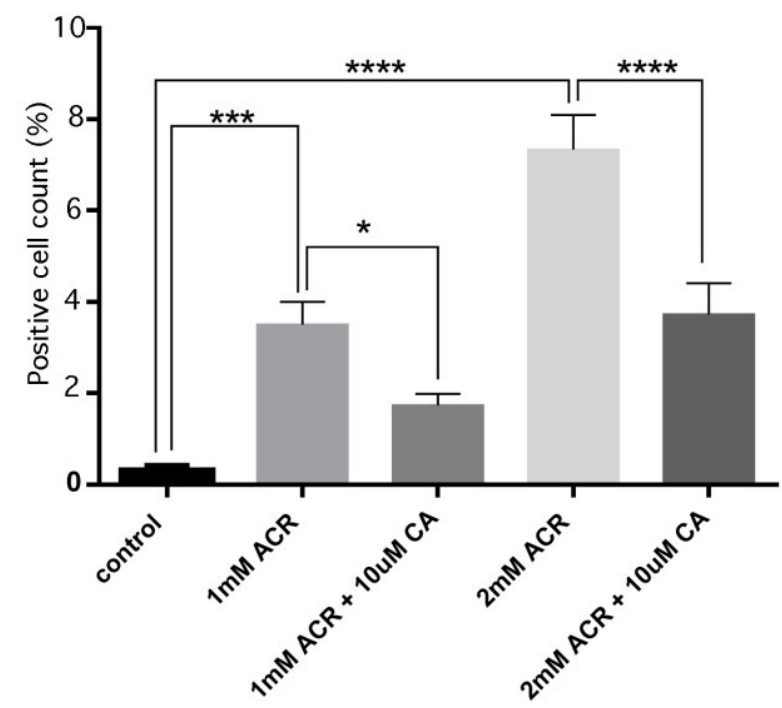


Figure 9

A

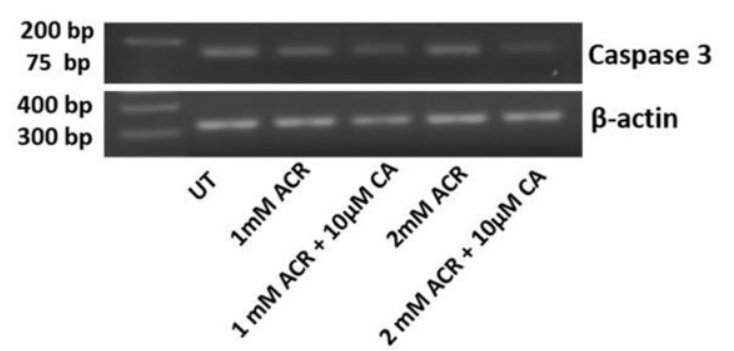

C

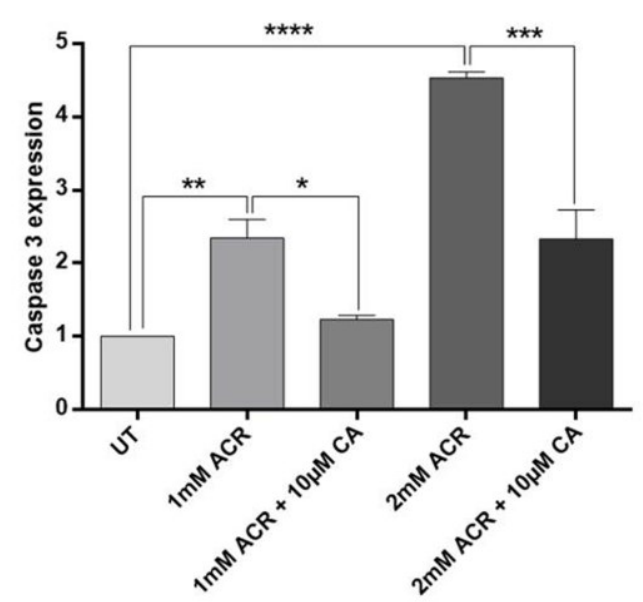

B

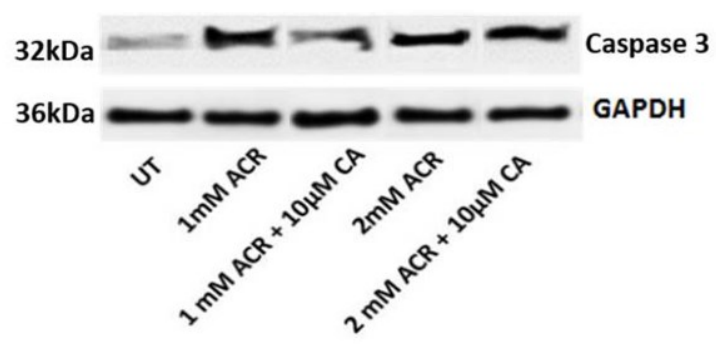

D

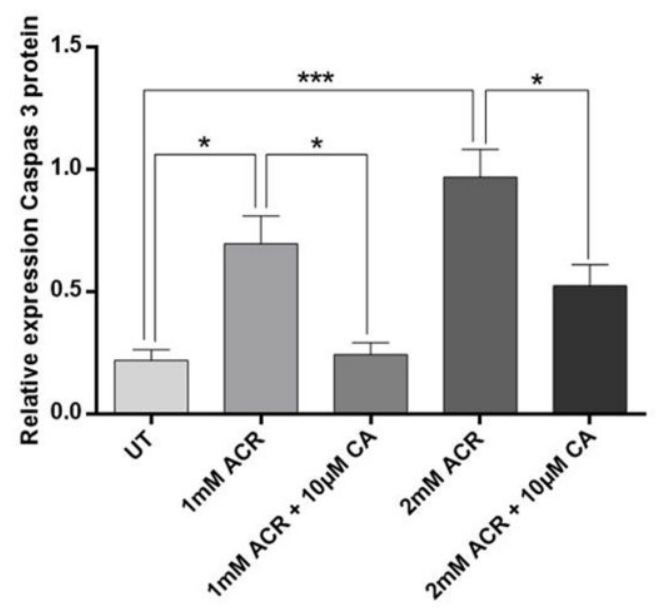

Figure S1
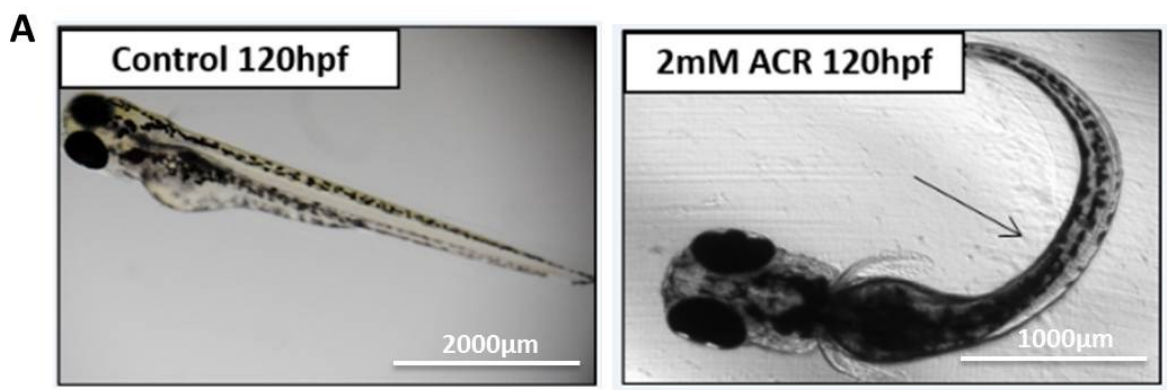

667
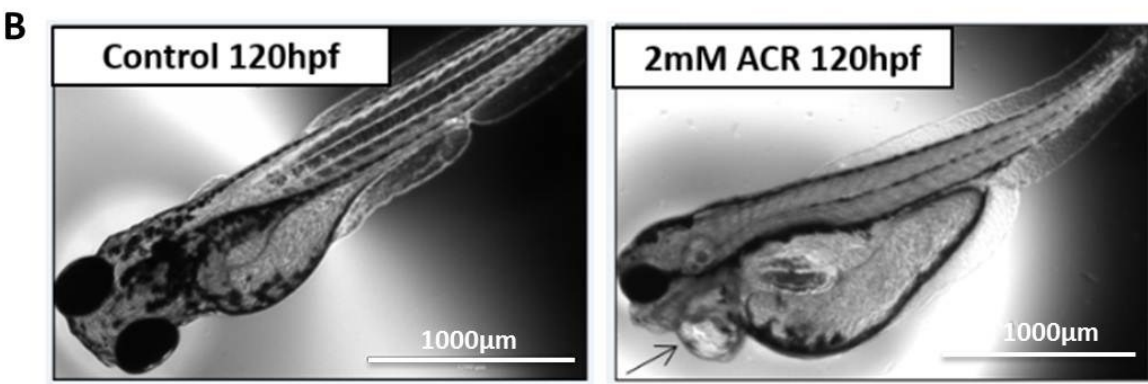